\title{
Recombinant Salmonella Bacteria Vectoring HIV/AIDS Vaccines
}

\author{
Nyasha Chin'ombe ${ }^{*}, 1,2$ and Vurayai Ruhanya ${ }^{1}$ \\ ${ }^{I}$ Department of Medical Microbiology, University of Zimbabwe, Harare, Zimbabwe \\ ${ }^{2}$ Division of Medical Virology, University of Cape Town, Cape Town, South Africa
}

\begin{abstract}
HIV/AIDS is an important public health problem globally. An affordable, easy-to-deliver and protective HIV vaccine is therefore required to curb the pandemic from spreading further. Recombinant Salmonella bacteria can be harnessed to vector HIV antigens or DNA vaccines to the immune system for induction of specific protective immunity. These are capable of activating the innate, humoral and cellular immune responses at both mucosal and systemic compartments. Several studies have already demonstrated the utility of live recombinant Salmonella in delivering expressed foreign antigens as well as DNA vaccines to the host immune system. This review gives an overview of the studies in which recombinant Salmonella bacteria were used to vector HIV/AIDS antigens and DNA vaccines. Most of the recombinant Salmonella-based HIV/AIDS vaccines developed so far have only been tested in animals (mainly mice) and are yet to reach human trials.
\end{abstract}

Keywords: Salmonella, bacteria, vectoring, HIV/AIDS, antigens, DNA, vaccines.

\section{INTRODUCTION TO SALMONELLA AND STRATEGIES FOR VECTORING VACCINES}

Salmonella bacteria infect their host via the intestine by crossing the epithelial barrier through the $\mathrm{M}$ cells overlying lymphoid follicles [1.2]. The translocation of Salmonella into the Peyer's patches of the intestine through the M cells is important for the systematic spread of the bacteria to distant organs such as the spleen and liver $[3,4]$. The bacteria are engulfed by the macrophages, dendritic cells and neutrophils, into which replication occurs $[5,6]$. To achieve this, the bacteria utilize the type-III secretion systems, (TTSS) designed to transport pathogenic proteins through both the bacterial and target host cell membranes [7]. Salmonella encode at least 2 virulence-associated TTSS. The first, Salmonella Pathogenicity Island 1 (SPI-1), is important for epithelial cell invasion and enteric pathogenesis [8,9]. The second pathogenicity island, SPI-2, is critical for intracellular pathogenesis and systemic infection by the bacteria $[8,10]$. After contact with target cells, TTSSmediated translocation of effector proteins occurs and this results in successful bacterial invasion [11]. SPI-2 gene expression is induced by phagocytosis and SPI-2 mutants cannot replicate efficiently within host cells [12]. Several other Salmonella pathogenicity islands such as SPI-3, SPI-4, SPI-5, SPI-6, SPI-7, SPI-8, SPI-9 and SPI-10 have also been identified and play various roles in intracellular survival and virulence of the bacteria [13-18]. Since most Salmonella enterica virulence genes are encoded on known pathogenicity islands, it is now possible to systematically attenuate the bacteria using genetic engineering tools in order to develop vaccines. These vaccines can be harnessed

*Address correspondence to this author at the Department of Medical Microbiology, University of Zimbabwe, P O Box A178, Avondale, Harare, Zimbabwe; Tel: +263-4-791-631, Ext. 2419; Fax: +263-4-792-245;

E-mail: nyasha.chinombe@gmail.com to carry foreign genes and can be used as recombinant vaccines. Other mutants of Salmonella generated or identified by traditional methods can also be used as vaccine vectors although some of them may be unsafe for use [1921]. Several reviews have been written on the feasibility of using attenuated recombinant Salmonella enterica to vector foreign antigens or DNA vaccines [22-28].

Two fundamentally different approaches are employed when using Salmonella to vector vaccines. The first approach involves the expression of the foreign antigens by the engineered recombinant bacterium. The foreign antigen genes are cloned on plasmid or onto the bacterial chromosome and the expression is driven by a prokaryotic promoter. The foreign antigens are expressed by the bacteria and presented to the immune system of the host after infection. In general, MHC Class II restricted and immunoglobulin responses are recorded in a number of studies [29-32]. However, other groups have also demonstrated the generation of MHC Class I-restricted CD8 + T cells after vaccination of animals with recombinant Salmonella expressing the foreign antigens [33-39]. The second approach to vector vaccines using recombinant Salmonella enterica involves the delivery of DNA vaccines by the bacteria $[40,41]$. The recombinant bacteria carrying the recombinant plasmid DNA harbouring foreign antigen gene under eukaryotic promoter enter the host cells for delivery. The host cells will use the host machinery to express the foreign antigens that can ultimately be presented to immune system $[42,43]$. The two approaches have already been used in development of candidate bacteria-vectored HIV-1 vaccines.

\section{RATIONALE OF USING RECOMBINANT SALMO- NELLA AS HIV-1 VACCINE VECTORS}

One of the key features of mucosal sites is the presence of $\mathrm{M}$ cells that play important roles in uptake and transport 
of pathogens $[2,44,45]$. HIV-1 and Salmonella utilize these $M$ cells in the mucosal surfaces as their gateways for systemic transmission [2,44,45]. Besides mucosal transmission, HIV-1 and Salmonella replication also occurs in the mucosal lymphoid tissue before systemic spread $[3,45,46]$. The MALT is rich in immune cells such as dendritic cells, macrophages, CD4+ and CD8+ T cells which play important roles in provoking mucosal immunity to HIV1 or Salmonella $[6,47]$. The rationale of using recombinant Salmonella to vector candidate HIV-1 vaccines is therefore based on the fact that the two pathogens use the same mode of infection. The two pathogens provoke the same type of immune responses, that is, innate, mucosal and systemic cellular and humoral immune responses [28,48-51]. In recent years, the innate immune responses to HIV, especially the role of NK cells have attracted a lot of interest in the development of HIV/AIDS vaccines. Recombinant Salmonella vectoring HIV/AIDS vaccines are capable of activating such immune responses that are also key in the induction of the adaptive responses [28]. Therefore Salmonella vectors can be exploited to deliver HIV-1 antigens for induction of protective mucosal and systemic immune responses to potentially block the invasion of HIV after sexual intercourse.

There are a number of advantages of using Salmonella as vectors for HIV-1 vaccines. The recombinant bacteria can be used as oral vaccines that can be delivered easily. Vaccineinduced immune responses or protection can be achieved at mucosal surfaces as well as in the systemic compartments [52]. The bacteria are capable of stimulating broad humoral as well as cell-mediated immune responses in both mucosal and systematic lymphoid tissues $[52,53]$. The bacteria are fast growing and vaccines can therefore be manufactured expeditiously. Several genetic engineering techniques developed for $E$. coli manipulation can be applied to Salmonella easily as the two bacteria are closely related $[52,54]$. Attenuation of specific Salmonella genes to generate vaccines can now easily be done using recombinant DNA technology. Salmonella also possess intrinsic adjuvantic properties that will make the vaccines very immunogenic [55]. Despite disarmed virulence, attenuated recombinant Salmonella can still colonize the lymphoid tissues after inoculation, but they do not cause disease. They are therefore safe for use and can even be used in HIV-positive patients $[54,56]$.

\section{RECOMBINANT SALMONELLA VECTORS EXPRES- SING HIV-1 VACCINE ANTIGENS}

Recombinant Salmonella expressing HIV-1 antigens have a great potential in the development of vaccines to curb AIDS globally. A number of studies have already been done in which recombinant Salmonella-vectored HIV-1 antigens were tested, mostly in small animals such as mice. Generally, HIV-1 antigens can be expressed by the recombinant Salmonella bacterium either from its chromosome harboring the HIV-1 gene or from a plasmid carrying the gene. Chromosomal integration has the advantage of increasing the stability of foreign antigens and also protects them against proteolytic degradation $[52,57]$. Expression of genes from the plasmid has the advantage of increasing gene dosage [58]. The expressed antigens can be presented to the immune system after uptake of the bacterium by the host.

A recombinant Salmonella enterica serovar Typhi constitutively expressing HIV-1 gp120 from the bacterial chromosome was previously constructed [59]. High levels of the gp120 were shown to be expressed by the vector [59]. The same antigen was also cloned chromosomally and expressed in recombinant Salmonella enterica serovar Typhimurium and its immunogenicity evaluated in mice [60]. Another recombinant Salmonella enterica serovar Typhimurium expressing the antigen episomally from a multicopy plasmid was constructed by the same group [60]. The recombinant Salmonella expressed more gp120 from the plasmid than from the chromosome [60]. Oral vaccination of mice with the two recombinant Salmonella vaccines did not induce HIV-1 env-specific CD8+ T cell responses or a significant antibody response [60]. However, there was some gp120-specific Th1 response in mice vaccinated with the Salmonella vector expressing gp120 from the plasmid [60]. This was the first study to demonstrate that a recombinant Salmonella expressing cytoplasmic HIV-1 gp120 could induce an immune response in mice. Later, recombinant Salmonella expressing the HIV-1 gp120 on the bacterial surface was constructed and found to be more immunogenic than the one expressing the antigen in the bacterial cytoplasm [61]. Another recombinant Salmonella expressing a truncated derivative of HIV-1 gp120 and displayed in the bacterial periplasm was later constructed and found to be highly immunogenic after only a single inoculation of mice [62]. The vector induced systemic gp120-specific splenic CD4+ Th1 and Th2 responses in the spleen after vaccination of mice [62]. The vector also induced strong mucosal gp120specific IgA antibody-secreting cell responses [62]. This study clearly demonstrated that recombinant Salmonellavectored secreted HIV-1 antigens could induce better T cell responses than those expressed cytoplasmically. More recently, a recombinant Salmonella enterica serovar Typhi expressing HIV-1 gp120 from a plasmid and HIV-1 Gag from the bacterial chromosome was constructed and tested [63]. Mice inoculated intranasally with the recombinant vector elicited high titers of gp120-specific $\operatorname{IgG}$ in the sera and gp120-specific IgA in fecal washes [63]. Systemic Gagspecific and gp120-specific CD8+ $\mathrm{T}$ cell responses were also induced in vaccinated animals [63]. This study further highlighted that recombinant Salmonella bacteria could potentially be used to vector HIV/AIDS vaccines. It is now generally accepted that induction of HIV-1 envelope-specific humoral responses is very critical in developing successful HIV vaccines. Although recombinant Salmonella may induce Env-specific humoral responses as shown by the studies mentioned above, the antibodies are unlikely to be neutralizing since the Env expressed by the bacteria lacks post-translational modifications found in nature. However, the Env-specific CD8+ and CD4+ T cell responses elicited by the recombinant bacteria should have the potential to protect against HIV infection. The non-neutralizing Envspecific antibodies induced by the bacteria may also have the potential to protect against HIV infection through antibodydependent cell-mediated pathway.

Salmonella enterica vaccine vectors have also been used to express HIV-1 Gag antigens [reviewed in 28]. Most of the studies have shown that Gag expressed in Salmonella could 
provoke HIV-specific immune responses in mice [28]. Briefly, recombinant Salmonella expressing HIV-1 Subtype C Gag elicited Gag-specific CD4+ Th1 and Th2 cytokine responses as well as Gag-specific IgG1 (Th1) and IgG2a (Th2) responses [29]. Recombinant Salmonella enterica serovar Typhimurium vaccine secreting HIV-Gag (p24) using the hemolysin secretorial signal of $E$. coli was also shown to elicit Gag-specific humoral and $\mathrm{T}$ cell responses in mice [64]. A recombinant Salmonella expressing HIV-1 Gag fused to the secretable bacterial Type III secretion system SopE protein elicited Salmonella-specific mucosal immune responses in vaccinated human volunteers, but no HIV-Gag specific responses were detected after a single dose [65]. Boosting with the same recombinant vector could have induced HIV-Gag-specific responses. Recombinant Salmonella enterica serovar Typhi expressing HIV-1 Gag from the bacterial chromosome also elicited systemic Gagspecific cytotoxic $\mathrm{T}$ lymphocyte responses in mice vaccinated intranasally [63]. Recombinant Salmonella vaccine vector expressing codon optimized HIV-1 Gag induced Gag-specific mucosal CD8+ $\mathrm{T}$ cell and humoral responses in mice vaccinated orally [66]. Other HIV-1 antigens have also been expressed in recombinant Salmonella vaccine vectors for delivering to the immune system. In our previous study, we successfully overexpressed codon-optimized HIV-1 Tat and Nef in Salmonella enterica serovar Typhimurium [67]. Animal studies to investigate the immunogenicity of the recombinant Salmonella expressing the two antigens are underway. All these studies showed that recombinant Salmonella could vector an HIV antigen, Gag, to induce specific immune responses. So far the target antigens for expression in recombinant Salmonella have been Env and Gag. These antigens have most of the B- and T-cell epitopes which are important in induction of protective immune response against HIV/AIDS infection [68-70].

\section{RECOMBINANT SALMONELLA VECTORS DELIVE- RING HIV DNA VACCINES}

The use of naked DNA as vaccines was originally demonstrated about two decades ago [71]. Since then, naked DNA vaccines have been used for induction of potent immune responses, especially cell-mediated [72,73]. The DNA inoculated by intradermal or intramuscular injection is taken by professional antigen presenting cells such as macrophages and dendritic cells which express the foreign antigen for presentation and induction of specific immune response [74]. In recent years, it has been demonstrated that Salmonella vaccines can vector naked DNA vaccines to deliver these DNA vaccines directly to the antigenpresenting cells such as macrophages and dendritic cells [23,74-78]. A number of studies have already demonstrated that recombinant Salmonella vectors can deliver HIV/AIDS DNA vaccines. Most of the studies have been done in animal models.

HIV-1 DNA vaccines delivered by recombinant Salmonella have been constructed. Most of the vaccines developed so far were based on the HIV-1 env (gp160) gene. A recombinant Salmonella Env DNA vaccine vector was constructed and used to vaccinate mice intragastrically [78]. Both mucosal and systemic HIV-1 Env-specific CD8+ T-cell responses were induced in vaccinated mice [78]. The plasmid HIV-1 Env DNA vaccine delivered intramuscularly only generated systemic but not mucosal CD8 $+\mathrm{T}$ cell responses in the vaccinated animals [78]. Such vaccineinduced $\mathrm{T}$ cell responses are very important in protecting or controlling sexual HIV transmission. This study was the first to demonstrate the feasibility of using recombinant Salmonella in vectoring HIV-1 DNA vaccine to induce specific cellular immune responses. Later, recombinant Salmonella and Shigella were compared in the capacity to vector the HIV-1 Env DNA vaccine [79]. Better cellular immune responses were generated by the recombinant Shigella than by the Salmonella [79]. This could be because the Shigella normally escapes the phagosome into the cytosol while the Salmonella remains confined in the phagosome. To further improve the immunogenicity of recombinant Salmonella vector, the HIV-1 Env (gp120) DNA vaccine was constructed with the gp120 and cholera toxin catalytic domain (CTA1) genes co-expressed [80]. Mice vaccinated with recombinant Salmonella vectoring the DNA vaccine co-expressing Env and CTA1 induced HIV-1 gp120-specific IgG responses that were more than 1000-fold greater than in mice vaccinated with a vector delivering the DNA vaccine only expressing the gp120 antigen [80]. The mice vaccinated with recombinant Salmonella delivering the DNA vaccine expressing gp120 and CTA1 also generated significantly more gp120-specific IFN-gamma ELISPOTs than mice vaccinated with the Salmonella carrying DNA expressing gp120 DNA vaccine alone [80]. These results demonstrated that HIV-1 DNA vaccines could be vectored more efficiently by recombinant Salmonella when adjuvants such as the cholera toxin were used. Recombinant Salmonella enterica serovar Typhimurium delivering an HIV-1 DNA vaccine expressing a polyepitope protein (composed of more than 80 CTL epitopes from HIV-1 subtype A, B and C proteins) was previously evaluated. The recombinant Salmonella elicited better HIV specific serum antibody, proliferative and CTL responses than by naked DNA vaccine in vaccinated mice [81]. The ability of recombinant Salmonella enteritidis to vector the same HIV-1 DNA vaccine was also later evaluated by the same research group [82]. Mice vaccinated with the Salmonella vector elicited both HIV-1 -specific humoral and cellular responses [82]. This study further demonstrated the capacity of recombinant Salmonella bacteria in vectoring even HIV-1 DNA vaccines expressing polyepitopes. HIV-1 Gag (p24) DNA vaccine was successfully delivered using recombinant Salmonella in mice which elicited HIV-specific immune responses [64]. An adjuvant, MCP3 was used to improve the immunogenicity of the Salmonella vector [64].

The use of bacterial ghosts as a vaccine delivery platform has gained momentum in recent years [83-85]. Some of them have been found to be immunogenic [86]. Recently, recombinant Salmonella typhi Ty21a carrying HIV-1 gp140 DNA vaccine has been used as bacterial ghosts (BGs) [87]. It was demonstrated that the Ty21a BGs carrying the HIV-1 gp140 DNA vaccine could be taken up and efficiently expressed by macrophages [87]. Mice inoculated with BGsDNA vaccine elicited significantly higher immune responses than those inoculated with the plasmid DNA vaccine alone [87]. The results demonstrated that recombinant Salmonella bacterial ghosts could be used to vector HIV-1 DNA vaccines. 
The use of heterologous prime-boost vaccination strategies to induce better cellular and humoral responses to vaccination has become popular in development of HIV vaccines in recent years. This has been successful especially when DNA and viral vectors are used to deliver HIV vaccines. In literature, we did not come across studies in which recombinant Salmonella vectoring was used in heterologous prime-boost strategy. We hope future Salmonella-based vaccines should employ this strategy since it may improve the immune responses elicited.

\section{ANTI-SALMONELLA PRE-EXISTING IMMUNITY AND VECTORING OF HIV-1 VACCINES}

The existence of prior immunity to vaccine vectors needs to be considered when developing vaccines for HIV/AIDS. This comes after one of the HIV/AIDS vaccines vectored by a recombinant adenovirus failed to induce the expected immune responses, but enhanced infection [88]. The impact of pre-existing anti-vector immunity on the efficiency of recombinant Salmonella vaccine vectors in delivering foreign antigens is still poorly understood. It is currently not clear whether prior exposure to Salmonella enhances or decreases the immune response to vectored antigens. In early studies, it has been found that pre-existing Salmonella immunity in mice improved their subsequent humoral and mucosal immune responses [89]. These observations were later supported by studies which showed that antibody responses to a viral antigen expressed by a recombinant Salmonella were enhanced in mice that were previously primed with the vector alone [90]. It was also demonstrated that secondary immune responses to a recombinant Salmonella expressing Streptococcus mutans antigen were not affected by pre-existing immunity [91]. In humans vaccinated with recombinant Salmonella enterica serovar Typhi Ty21a expressing Helicobacter. pylori ureases A and $\mathrm{B}$, it was shown that that prior vector immunity enhanced immune responses to the foreign antigens [92]. It was also shown that animals previously exposed to the vector induced much higher $\mathrm{CD} 8+\mathrm{T}$ cell responses when compared with animals that did not have any pre-existing Salmonella immunity [93]. These studies, though limited, suggest that prior exposure to the vector enhances immunogenicity to the heterologous antigens. The mechanisms of this enhancement of immune responses are not yet clear. However, it has been suggested that this could be due to enhanced uptake of antibody-coated vector by antigen-presenting cells such as macrophages and dendritic cells during antigen presentation [94]. However, contrasting results have been found in other studies. One study showed that pre-existing Salmonella immunity reduced memory serum responses and further interfered with immune response to the foreign antigen $[95,96]$. It was also shown that subsequent rapid clearance of the vector was due to better Salmonella-specific CD8+ T cell responses induced after initial priming [97]. After inoculation, the vector was cleared within 7 days, and after the second booster inoculation, the clearance was within 4 days [97]. Whether rapid clearance of the vector affects the immune response to the delivered antigen, is not clear. Some studies also showed that ability of the recombinant Salmonella vector to colonize was significantly compromised in animals that had previously been exposed to the vector [98]. A recent review of the literature has however concluded that recombinant bacterial vaccine vectors such as Salmonella, in most cases, enhance immunogenicity, mainly humoral immune responses, while for viral vectors such as adenovirus, pre-existing immunity hinders subsequent induction of cell-mediated responses [99]. Further research needs to be done to clarify whether pre-existing vector immunity will have any impact on the use of Salmonella bacterial vaccines vectors, especially in Africa, where the wild-type Salmonella enterica serovars are endemic.

\section{CONCLUSIONS}

This review shows that there is a growing body of literature on the use of recombinant Salmonella bacterial vaccines as potential delivery vectors for HIV/AIDS antigens and DNA vaccines. So far a number of Salmonellabased HIV/AIDS vaccines have already been tested in animal trials.

\section{CONFLICT OF INTEREST}

The authors declare no conflict of interest.

\section{ACKNOWLEDGEMENTS}

The authors acknowledge support from the South African National Research Foundation and University of Zimbabwe.

\section{REFERENCES}

[1] Finlay BB. Molecular and cellular mechanisms of Salmonella pathogenesis. Curr Top Microbiol Immunol 1994; 192: 163-85.

[2] Jones BD, Ghori N, Falkow S. Salmonella typhimurium initiates murine infection by penetrating and destroying the specialized epithelial M cells of the Peyer's patches. J Exp Med 1994; 180: 15 23.

[3] Jepson MA, Clark MA. The role of M cells in Salmonella infection. Microbes Infect 2001; 3: 1183-90.

[4] Grassl GA, Finlay BB. Pathogenesis of enteric Salmonella infections. Curr Opin Gastroenterol 2008; 24: 22-6.

[5] Wick MJ. Living in the danger zone: innate immunity to Salmonella. Curr Opin Microbiol 2004; 7: 51-7.

[6] Santos RL, Bäumler AJ. Cell tropism of Salmonella enterica. Int J Med Microbiol 2004; 294: 225-33.

[7] van der Heijden J, Finlay BB. Type III effector-mediated processes in Salmonella infection. Future Microbiol 2012; 7: 685-703.

[8] Agbor TA, McCormick BA. Salmonella effectors: important players modulating host cell function during infection. Cell Microbiol 2011; 13: 1858-69.

[9] Que F, Wu S, Huang R. Salmonella pathogenicity island 1(SPI-1) at work. Curr Microbiol 2013; 66: 582-7.

[10] Figueira R, Holden DW. Functions of the Salmonella pathogenicity island 2 (SPI-2) type III secretion system effectors. Microbiology 2012; 158: 1147-61.

[11] Hueck CJ. Type III protein secretion systems in bacterial pathogens of animals and plants. Microbiol Mol Biol Rev 1998; 62: 379-433.

[12] Shea JE, Hensel M, Gleeson C, Holden DW. Identification of a virulence locus encoding a second type III secretion system in Salmonella typhimurium. Proc Natl Acad Sci USA 1996; 93: 2593 7.

[13] Saroj SD, Shashidhar R, Karani M, Bandekar JR. Distribution of Salmonella pathogenicity island (SPI)-8 and SPI-10 among different serotypes of Salmonella. J Med Microbiol 2008; 57: 4247.

[14] Marcus SL, Brumell JH, Pfeifer CG, Finlay BB. Salmonella pathogenicity islands: big virulence in small packages. Microbes Infect 2000; 2: 145-56.

[15] Rychlik I, Karasova D, Sebkova A, et al. Virulence potential of five major pathogenicity islands (SPI-1 to SPI-5) of Salmonella enterica serovar Enteritidis for chickens. BMC Microbiol 2009; 9: 268.

[16] Hensel M. Evolution of pathogenicity islands of Salmonella enterica. Int J Med Microbiol 2004; 294: 95-102. 
[17] Hensel M. Genome-based identification and molecular analyses of pathogenicity islands and genomic islands in Salmonella enterica. Methods Mol Biol 2007; 394: 77-88.

[18] Amavisit P, Lightfoot D, Browning GF, Markham PF. Variation between pathogenic serovars within Salmonella pathogenicity islands. J Bacteriol 2003; 185: 3624-35.

[19] Stocker BA. Auxotrophic Salmonella typhi as live vaccine. Vaccine 1988; 6: 141-5.

[20] Hormaeche CE, Joysey HS, Desilva L, Izhar M, Stocker BA. Immunity induced by live attenuated Salmonella vaccines. Res Microbiol 1990; 141: 757-64.

[21] Stocker BA. Aromatic-dependent salmonella as anti-bacterial vaccines and as presenters of heterologous antigens or of DNA encoding them. J Biotechnol 2000; 83: 45-50.

[22] Sirard JC, Niedergang F, Kraehenbuhl JP. Live attenuated Salmonella: a paradigm of mucosal vaccines. Immunol Rev 1999; 171: 5-26.

[23] Shata MT, Stevceva L, Agwale S, Lewis GK, Hone DM. Recent advances with recombinant bacterial vaccine vectors. Mol Med Today 2000; 6: 66-71.

[24] Bumann D, Hueck C, Aebischer T, Meyer TF. Recombinant live Salmonella spp. for human vaccination against heterologous pathogens. FEMS Immunol Med Microbiol 2000; 27: 357-64.

[25] Garmory HS, Brown KA, Titball RW. Salmonella vaccines for use in humans: present and future perspectives. Fems Microbiol Rev 2002; 26: 339-53.

[26] Garmory HS, Leary SE, Griffin KF, Williamson ED, Brown KA, Titball RW. The use of live attenuated bacteria as a delivery system for heterologous antigens. J Drug Target 2003; 11: 471-9.

[27] Hegazy WA, Hensel M. Salmonella enterica as a vaccine carrier. Future Microbiol 2012; 7: 111-27.

[28] Chin'ombe, N. Recombinant Salmonella enterica serovar Typhimurium as a Vaccine Vector for HIV-1 Gag. Viruses 2013; 5: 2062-78.

[29] Chin'ombe N, Bourn WR, Williamson AL, Shephard EG. Oral vaccination with a recombinant Salmonella vaccine vector provokes systemic HIV-1 subtype C Gag-specific CD4+ Th1 and Th2 cell immune responses in mice. Virol J 2009; 6: 87.

[30] Sizemore DR, Warner B, Lawrence J, Jones, Killeen KP. Live attenuated Salmonella typhimurium vectoring Campylobacter antigens. Vaccine 2006; 24: 3793-803.

[31] Sztein MB. Cell-mediated immunity and antibody responses elicited by attenuated Salmonella enterica Serovar Typhi strains used as live oral vaccines in humans. Clin Infect Dis 2007; 45: S15-S19.

[32] Galen JE, Chinchilla M, Pasetti MF, et al. Mucosal immunization with attenuated Salmonella enterica serovar Typhi expressing protective antigen from anthrax toxin (PA83) primes monkeys for accelerated serum antibody responses to parenteral PA83 vaccine. J Infect Dis 2009; 199: 326-35.

[33] Chin'ombe N, Bourn WR, Williamson AL. Shephard EG. An oral recombinant Salmonella enterica serovar Typhimurium mutant elicits systemic antigen-specific CD8+ T cell cytokine responses in mice. Gut Pathogens 2009; 1: 9.

[34] Shams H, Poblete F, Russmann H, Galan JE, Donis RO. Induction of specific CD8+ memory $\mathrm{T}$ cells and long lasting protection following immunization with Salmonella typhimurium expressing a lymphocytic choriomeningitis MHC class I-restricted epitope. Vaccine 2001; 20: 577-85.

[35] Valentine PJ, Meyer K, Rivera MM, et al. Induction of SIV capsidspecific CTL and mucosal sIgA in mice immunized with a recombinant $S$. typhimurium aroA mutant. Vaccine 1996; 14: 13846.

[36] Catic A, Dietrich G, Gentschev I, Goebel W, Kaufmann SH, Hess J. Introduction of protein or DNA delivered via recombinant Salmonella typhimurium into the major histocompatibility complex class I presentation pathway of macrophages. Microbes Infect 1999; 1: 113-21.

[37] Verma NK, Ziegler HK, Stocker BA, Schoolnik GK. Induction of a cellular immune response to a defined T-cell epitope as an insert in the flagellin of a live vaccine strain of Salmonella. Vaccine 1995; 13: 235-44.

[38] Aggarwal A, Kumar S, Jaffe R, Hone D, Gross M, Sadoff J. Oral Salmonella: malaria circumsporozoite recombinants induce specific CD8+ cytotoxic T cells. J Exp Med 1990; 172: 1083-90.
[39] Gonzalez C, Hone D, Noriega FR, et al. Salmonella typhi vaccine strain CVD 908 expressing the circumsporozoite protein of Plasmodium falciparum: strain construction and safety and immunogenicity in humans. J Infect Dis 1994; 169: 927-31.

[40] Sizemore DR, Branstrom AA, Sadoff JC. Attenuated bacteria as a DNA delivery vehicle for DNA-mediated immunization. Vaccine 1997; 15: 804-7.

[41] Bauer H, Darji A, Chakraborty T, Weiss S. Salmonella-mediated oral DNA vaccination using stabilized eukaryotic expression plasmids. Gene Ther 2005; 12: 364-72.

[42] Niethammer AG, Primus FJ, Xiang R, et al. An oral DNA vaccine against human carcinoembryonic antigen (CEA) prevents growth and dissemination of Lewis lung carcinoma in CEA transgenic mice. Vaccine 2001; 20: 421-9.

[43] Woo PC, Wong LP, Zheng BJ, Yuen KY. Unique immunogenicity of hepatitis B virus DNA vaccine presented by live-attenuated Salmonella typhimurium. Vaccine 2001; 19: 2945-54.

[44] Amerongen HM, Weltzin R, Farnet CM, Michetti P, Haseltine WA, Neutra MR. Transepithelial transport of HIV-1 by intestinal M cells: the mechanism of transmission of AIDS. J Acquir Immune Defic Syndr 1991; 4: 760-5.

[45] Hathaway LJ, Kraehenbuhl JP. The role of M cells in mucosal immunity. Cell Mol Life Sci 2000; 57: 323-32.

[46] Mehandru S, Tenner-Racz K, Racz P, Markowitz M. The gastrointestinal tract is critical to the pathogenesis of acute HIV-1 infection. J Allergy Clin Immunol 2005; 116: 419-22.

[47] Neutra MR, Frey A, Kraehenbuhl JP. Epithelial M cells: gateways for mucosal infection and immunization. Cell 1996; 86: 345-8.

[48] Swart AL, Hensel M. Interactions of Salmonella enterica with dendritic cells. Virulence 2012; 3: 660-7.

[49] Jantsch J, Chikkaballi D, Hensel M. Cellular aspects of immunity to intracellular Salmonella enterica. Immunol Rev 2011; 240: 18595.

[50] Hughes R, Towers G, Noursadeghi M. Innate immune interferon responses to human immunodeficiency virus-1 infection. Rev Med Virol 2012; 22: 257-66.

[51] Gandhi RT, Walker BD. Immunologic control of HIV-1. Annu Rev Med 2002; 53: 149-72.

[52] Kotton CN, Hohmann EL. Enteric pathogens as vaccine vectors for foreign antigen delivery. Infect Immun 2004; 72: 5535-47.

[53] Galen JE, Pasetti MF, Tennant S, Ruiz-Olvera P, Sztein MB, Levine MM. Salmonella enterica serovar Typhi live vector vaccines finally come of age. Immunol Cell Biol 2009; 87: 400-12.

[54] Cheminay C, Hensel M. Rational design of Salmonella recombinant vaccines. Int J Med Microbiol 2008; 298: 87-98.

[55] Eom JS, Seok Kim J, Im Jang J, et al. Enhancement of Host Immune Responses by Oral Vaccination to Salmonella enterica serovar Typhimurium Harboring Both FliC and FljB Flagella. PLoS One 2013; 8: e74850.

[56] Banda R, Yambayamba V, Lalusha BD, Sinkala E, Kapulu MC, Kelly P. Safety of live, attenuated oral vaccines in HIV-infected Zambian adults: oral vaccines in HIV. Vaccine 2012; 30: 5656-60.

[57] Galen JE, Levine MM. Can a 'flawless' live vector vaccine strain be engineered? Trends Microbiol 2001; 9: 372-6.

[58] Wang JY, Harley RH, Galen JE. Novel methods for expression of foreign antigens in live vector vaccines. Hum Vaccin Immunother 2013; 9: 1558-64.

[59] Fouts TR, Lewis GK, Hone DM. Construction and characterization of a Salmonella typhi-based human immunodeficiency virus type 1 vector vaccine. Vaccine 1995; 13: 561-9.

[60] Fouts TR, Tuskan RG, Chada S, Hone DM, Lewis GK. Construction and immunogenicity of Salmonella typhimurium vaccine vectors that express HIV-1 gp120. Vaccine 1995; 13: 1697-705.

[61] Hone DM, Wu S, Powell RJ, et al. Optimization of live oral Salmonella-HIV-1 vaccine vectors for the induction of HIVspecific mucosal and systemic immune responses. J Biotechnol 1996; 44: 203-7.

[62] Wu S, Pascual DW, Lewis GK, Hone DM. Induction of mucosal and systemic responses against human immunodeficiency virus type 1 glycoprotein 120 in mice after oral immunization with a single dose of a Salmonella-HIV vector. AIDS Res Hum Retroviruses 1997; 13: 1187-94.

[63] Feng Y, Wang S, Luo F, et al. A novel recombinant bacterial vaccine strain expressing dual viral antigens induces multiple 
immune responses to the Gag and gp120 proteins of HIV-1 in immunized mice. Antiviral Res 2008; 80: 272-9.

[64] Bachtiar EW, Coloe PJ, Smooker PM. Construction and immunogenicity of Salmonella vaccine vector expressing HIV-1 antigen and MCP3. Acta Microbiol Immunol Hung 2009; 56: 40315.

[65] Kotton CN, Lankowski AJ, Scott N, et al. Safety and immunogenicity of attenuated Salmonella enterica serovar Typhimurium delivering an HIV-1 Gag antigen via the Salmonella Type III secretion system. Vaccine 2006; 24: 6216-24.

[66] Tsunetsugu-Yokota Y, Ishige M, Murakami M. Oral attenuated Salmonella enterica serovar Typhimurium vaccine expressing codon-optimized HIV type $1 \mathrm{Gag}$ enhanced intestinal immunity in mice. AIDS Res Hum Retroviruses 2007; 23: 278-86.

[67] Chin'ombe N, Lebeko M, Kgatle M. Overexpression of recombinant HIV-1 Subtype C Tat and Nef in a Salmonella vaccine vector. Pan Afr Med J 2013; 16: 19.

[68] Masemola AM, Mashishi TN, Khoury G, et al. HIVNET 028 Study Team. Novel and promiscuous CTL epitopes in conserved regions of Gag targeted by individuals with early subtype C HIV type 1 infection from southern Africa. J Immunol 2004; 173: 4607-17.

[69] Ferrari G, Kostyu DD, Cox J, et al. Identification of highly conserved and broadly cross-reactive HIV type 1 cytotoxic $\mathrm{T}$ lymphocyte epitopes as candidate immunogens for inclusion in Mycobacterium bovis BCG-vectored HIV vaccines. AIDS Res Hum Retroviruses 2000; 16: 1433-43.

[70] Gottardo R, Bailer RT, Korber BT, et al. Plasma IgG to Linear Epitopes in the V2 and V3 Regions of HIV-1 gp120 Correlate with a Reduced Risk of Infection in the RV144 Vaccine Efficacy Trial. PLoS One 2013; 8: e75665.

[71] Wolff JA, Malone RW, Williams P, et al. Direct gene transfer into mouse muscle in vivo. Science 1990; 247: 1465-8.

[72] Ulmer JB, Donnelly JJ, Liu MA. Toward the development of DNA vaccines. Curr Opin Biotechnol 1996; 7: 653-8.

[73] Donnelly JJ, Wahren B, Liu MA. DNA vaccines: progress and challenges. J Immunol 2005; 175: 633-9.

[74] Schoen C, Stritzker J, Goebel W, Pilgrim S. Bacteria as DNA vaccine carriers for genetic immunization. Int $\mathrm{J}$ Med Microbiol 2004: 294: 319-35.

[75] Dietrich G, Spreng S, Favre D, Viret JF, Guzman CA. Live attenuated bacteria as vectors to deliver plasmid DNA vaccines. Curr Opin Mol Ther 2003; 5: 10-9.

[76] Xu F, Ulmer JB. Attenuated Salmonella and Shigella as carriers for DNA vaccines. J Drug Target 2003; 11: 481-8.

[77] Loessner H, Weiss S. Bacteria-mediated DNA transfer in gene therapy and vaccination. Expert Opin Biol Ther 2004; 4: 157-68.

[78] Shata MT, Reitz MS Jr, DeVico AL, Lewis GK, Hone DM. Mucosal and systemic HIV-1 Env-specific CD8(+) T-cells develop after intragastric vaccination with a Salmonella Env DNA vaccine vector. Vaccine 2001; 20: 623-9.

[79] Vecino WH, Morin PM, Agha R, Jacobs WR Jr, Fennelly GJ. Mucosal DNA vaccination with highly attenuated Shigella is superior to attenuated Salmonella and comparable to intramuscular DNA vaccination for T cells against HIV. Immunol Lett 2002; 82: 197-204.

[80] Bagley KC, Shata MT, Onyabe DY, et al. Immunogenicity of DNA vaccines that direct the coincident expression of the $120 \mathrm{kDa}$ glycoprotein of human immunodeficiency virus and the catalytic domain of cholera toxin. Vaccine 2003; 21: 3335-41.

[81] Karpenko LI, Nekrasova NA, Ilyichev AA, et al. Comparative analysis using a mouse model of the immunogenicity of artificial VLP and attenuated Salmonella strain carrying a DNA-vaccine encoding HIV-1 polyepitope CTL-immunogen. Vaccine 2004; 22 : $1692-9$.
[82] Karpenko LI, Danilenko AV, Bazhan SI, et al. Attenuated Salmonella enteritidis E23 as a vehicle for the rectal delivery of DNA vaccine coding for HIV-1 polyepitope CTL immunogen. Microb Biotechnol 2012; 5: 241-50.

[83] Lubitz W, Witte A, Eko FO, et al. Extended recombinant bacterial ghost system. J Biotechnol 1999; 73: 261-73.

[84] Szostak MP, Hensel A, Eko FO, et al. Bacterial ghosts: nonliving candidate vaccines. J Biotechnol 1996; 44: 161-70.

[85] Jalava K, Eko FO, Riedmann E, Lubitz W. Bacterial ghosts as carrier and targeting systems for mucosal antigen delivery. Expert Rev Vaccines 2003; 2: 45-51.

[86] Mayr UB, Haller C, Haidinger W, et al. Bacterial ghosts as an oral vaccine: a single dose of Escherichia coli O157:H7 bacterial ghosts protects mice against lethal challenge. Infect Immun 2005; 73: 4810-7.

[87] Wen J, Yang Y, Zhao G, et al. Salmonella typhi Ty21a bacterial ghost vector augments HIV-1 gp140 DNA vaccine-induced peripheral and mucosal antibody responses via TLR4 pathway. Vaccine 2012; 30: 5733-9.

[88] Cheng C, Wang L, Gall JG, et al. Decreased Pre-existing Ad5 Capsid and Ad35 Neutralizing Antibodies Increase HIV-1 Infection Risk in the Step Trial Independent of Vaccination. PLoS ONE 2012; 7: e33969.

[89] Bao JX, Clements JD. Prior immunologic experience potentiates the subsequent antibody response when Salmonella strains are used as vaccine carriers. Infect Immun 1991; 59: 3841-5.

[90] Whittle BL, Verma NK. The immune response to a B-cell epitope delivered by Salmonella is enhanced by prior immunological experience. Vaccine 1997; 15: 1737-40.

[91] Jespersgaard C, Zhang P, Hajishengallis G, Russell MW, Michalek SM. Effect of attenuated Salmonella enterica serovar Typhimurium expressing a Streptococcus mutans antigen on secondary responses to the cloned protein. Infect Immun 2001; 69: 6604-11.

[92] Bumann D. Regulated antigen expression in live recombinant Salmonella enterica serovar Typhimurium strongly affects colonization capabilities and specific CD4(+)-T-cell responses. Infect Immun 2001; 69: 7493-500.

[93] Sevil-Domenech VE, Panthel K, Winter SE, Russmann H. Heterologous prime-boost immunizations with different Salmonella serovars for enhanced antigen-specific CD8 T-cell induction. Vaccine 2008; 26: 1879-86.

[94] Igietseme JU, Eko FO, He Q, Black CM. Antibody regulation of T cell immunity: implications for vaccine strategies against intracellular pathogens. Expert Rev Vaccines 2004; 3: 23-34.

[95] Attridge SR, Davies R, LaBrooy JT. Oral delivery of foreign antigens by attenuated Salmonella: consequences of prior exposure to the vector strain. Vaccine 1997; 15: 155-62.

[96] Roberts M, Bacon A, Li J, Chatfield S. Prior immunity to homologous and heterologous Salmonella serotypes suppresses local and systemic anti-fragment $\mathrm{C}$ antibody responses and protection from tetanus toxin in mice immunized with Salmonella strains expressing fragment C. Infect Immun 1999; 67: 3810-5.

[97] Domenech VE, Panthel K, Meinel KM, Russmann H. Rapid clearance of a recombinant Salmonella vaccine carrier prevents enhanced antigen-specific CD8 T-cell responses after oral boost immunizations. Microbes Infect 2005; 7: 860-6.

[98] Gahan ME, Webster DE, Wijburg OL, Wesselingh SL, Strugnell RA. Impact of prior immunological exposure on vaccine delivery by Salmonella enterica serovar Typhimurium. Vaccine 2008; 26 : 6212-20.

[99] Saxena M, Van TT, Baird FJ, Coloe PJ, Smooker PM. Pre-existing immunity against vaccine vectors - friend or foe? Microbiology 2013; 159: 1-11. 